\title{
Dünya genelinde COVID-19 pandemisi yaygınlığı ile ilişkili faktörlere yönelik bir ekolojik çalışma
}

\author{
An ecological study of factors associated with the prevalence of the COVID-19 \\ pandemic worldwide
}

\author{
Ceren Oğuz, Özgür Sevinç, Erkan Barış
}

Gönderilme tarihi:24.09.2020

Kabul tarihi:03.03.2021

Öz

Amaç: COVID-19 salgınında ülkelerdeki vaka, ölüm ve test sayılarıyla ülkelerin Gini katsayıları, yaşlı nüfus oranları, ekvatora uzaklıkları ve küresel sağlık güvenliği endeksleri arasındaki ilişkilerin değerlendirilmesidir.

Gereç ve yöntem: Ağustos 2020 tarihinde yapılan ekolojik tipteki bu araştımada ülkelerin COVID-19 salgını yaygınlığı ile ilgili Worldometers internet sitesinde raporlanan verileri kullanılmıştır. Ülkelerin COVID-19 ilişkili değişkenleri ile Gini katsayıları, yaşlı nüfus popülasyonları, ekvatora uzaklıkları ve küresel sağlık güvenliği endeksleri arasındaki ilişkiye bakılmıştır.

Bulgular: Araştırmada 215 ülke değerlendirmeye alınmışırı. Milyonda toplam vaka sayısının en fazla görüldüğü ülke Katar iken; milyonda toplam ölüm sayısı en fazla San Marino'da, milyonda toplam test sayısı en fazla Monako'dadır. Doğrusal regresyon analizi sonucunda ülkelerin Gini katsayıları milyonda toplam vaka sayısı ile; yaşlı nüfus oranları milyonda toplam ölüm sayısı ile; ekvatora uzakııkları milyonda toplam test sayısı ile iliş̧kili bulunmuştur. Ülkelerin Gini katsayıları arttıkça milyonda toplam vaka sayıları $(p=0,006)$; yaşı nüfus oranları arttıkça milyonda ölüm sayıları $(p=0,005)$; ekvatora uzakıkları arttıkça milyonda test sayıları $(p=0,015)$ artmaktadır.

Sonuç: Sonuç olarak gelir eşitsizliği, yaşlı nüfus, ekvatora uzaklık artıkça salgından etkilenim artmaktadır.

Anahtar kelimeler: COVID-19, pandemi, gini katsayıSı, küresel sağıık güvenliği endeksi.

Oğuz C, Sevinç Ö, Barış E. Dünya genelinde COVID-19 pandemisi yaygınlığı ile ilişkili faktörlere yönelik bir ekolojik çalışma. Pam Tıp Derg 2021;14:574-583.

\section{Abstract}

Purpose: The aim is to evaluate the relationships between the number of cases, deaths and tests in countries in the COVID-19 outbreak and the countries' Gini coefficients, elderly population rates, distances to the equator and global health security indexes.

Materials and methods: In this ecological study conducted in August 2020, the data reported on the Worldometers website on the prevalence of the COVID-19 outbreak were used. The relationship between COVID-19 related variables of countries and Gini coefficients, elderly population ratios, distance from the equator and global health security indexes were examined.

Results: 215 countries were evaluated in the study. Qatar is the country with the highest number of cases per million; San Marino has the highest number of deaths per million and Monaco has the highest number of tests per million. As a result of the linear regression analysis, the Gini coefficients of the countries were associated with the total number of cases per million, the elderly population ratios were associated with the total number of deaths per million, and distance to the equator was associated with the total number of tests per million. As the Gini coefficients of the countries increase, the total number of cases per million $(p=0.006)$; as the elderly population rates increase, deaths per million $(p=0.005)$; as the distance from the equator increases, the number of tests per million $(p=0.015)$ increases.

Conclusion: As a result, as income inequality, elderly population and distance from the equator increase, the impact from the pandemic increases.

Key words: COVID-19, pandemic, gini coefficient, global health security index.

Oguz C, Sevinc O, Barıs E. An ecological study of factors associated with the prevalence of the COVID-19 pandemic worldwide. Pam Med J 2021;14:574-583.

Ceren Oğuz, Arş. Gör. Dr. Pamukkale Üniversitesi Tıp Fakültesi, Halk Sağlığı Anabilim Dalı, Denizli, Türkiye, e-posta: drcerenoguz@gmail.com (https://orcid.org/0000-0002-6510-3487 (Sorumlu Yazar)

Özgür Sevinç, Doç. Dr. Pamukkale Üniversitesi Tıp Fakültesi, Halk Sağı̆̆ı Anabilim Dalı, Denizli, Türkiye, e-posta: ozgursevinc@gmail.com (https://orcid.org/0000-0002-3231-8123)

Erkan Barış, Arş. Gör. Dr. Pamukkale Üniversitesi Tıp Fakültesi, Halk Sağı̆̆ı Anabilim Dalı, Denizli, Türkiye, e-posta: erkanb@pau.edu.tr (https://orcid.org/0000-0001-9198-7725) 


\section{Giriş}

Koronavirüsler (CoV), soğuk algınlığına neden olan diğer etkenler gibi toplumda yaygın görülür. Kendi kendini sınırlayan hafif enfeksiyon tablolarına neden olabildiği gibi daha ciddi enfeksiyon tablolarına ve büyük salgınlara neden olabilir. Bu virüsler yarasa koronavirüslerine yakın bir genetik yapıya sahip olmasına rağmen türler arası çapraz geçişler değişime neden olmakta ve ara konaklar nedeniyle yeni insan virüsleri meydana gelmektedir [1]. Ağır Akut Solunum Sendromu (Severe Acute Respiratory Syndrome, SARS) ve Orta Doğu Solunum Sendromu (Middle East Respiratory Syndrome, MERS) bu tablolara örnektir [2-5].

31 Aralık 2019'da Dünya Sağlık Örgütü (DSÖ) Çin Ülke Ofisi tarafından Çin'in Vuhan şehrinde etiyolojisi bilinmeyen pnömoni vakaları bildirilmiştir. 7 Ocak 2020'de etkenin daha önce insanlarda tespit edilmemiş yeni bir koronavirüs (2019- nCoV) olduğu gösterilmiştir ve SARS CoV'e benzerliği nedeniyle SARSCoV-2 olarak adlandırımıştır [1]. COVID-19 için mevcut kanitlar, SARS-CoV-2'nin zoonotik bir kaynağa sahip olduğunu göstermekle birlikte bu kaynağın ne olduğu henüz tanımlanmamıştır [6]. Vakaların aylar içinde yayılım göstermesi sonucunda Dünya Sağlık Örgütü 11 Mart 2020'de COVID-19 salgınını pandemi olarak ilan etmiştir [7].

Veri tabanını oluşturduğumuz ve salgının 214. günü olan 31 Temmuz 2020 itibariyle toplam vaka sayısı Dünya genelinde 17573586 ve Türkiye'de 229891'dir. Ölüm sayıları ise Dünya'da 678579 kişi ve Türkiye'de 5674 kişi sayısına ulaşmıştır [8]. Yüksek ölüm oranlarına sahip olan COVID-19 salgını hem Türkiye hem de Dünya açısından ciddi bir halk sağlığı sorunudur.

Hassas bir popülasyonda hastalık spektrumunu ve hastalığın patojenik mekanizmasını anlamak, özellikle pandemi sırasında önemlidir. Hastalık şiddeti spektrumu; triyajı, tanısal ve terapötik tedaviye karar vermeyi ve prognostik beklentileri etkiler; bu nedenle yaşa göre COVID-19 ile ilişkili morbidite ve mortaliteyi anlamak önemlidir. COVID-19 salgını sırasında, hastalık yükünde yaşa bağlı bir artış olduğu düşünülmüştür [7]. Yaş ve COVID-19 ile bağlantılı morbidite veya mortalite arasındaki ilişki sağlık uzmanları ve genel nüfus arasında da ele alınmıştır. Enfekte hastaların tıbbi sistemlerin sınırlarını aşması, tedavi yoğunluğunu belirlemede yaşın dikkate alınması gerekip gerekmediği konusunda sosyal kaygıları artırmıştır [9]. Gençlerin hastalık durumunun nispeten daha az şiddetli olduğu algısı, bazı bölgelerde enfeksiyonu önleme konusundaki farkındalıkların da azalmasına sebep olmuştur [7].

COVID-19 enfeksiyonuna yatkın olduğu düşünülen demografik, sosyoekonomik ve hatta coğrafik faktörlerin Dünya için büyük bir tehdit oluşturan COVID-19 salgını üzerine etkisini incelemek önemlidir. Bu amaç doğrultusunda çalışmamızda, COVID-19 salgınında ülkelerdeki vaka, ölüm ve test sayılarıyla ülkelerin ekvatora uzaklıkları, yaşıı nüfus oranları, Gini katsayıları (milli gelir dağılımı) ve küresel sağlık güvenliği endeksleri (GHS) arasındaki ilişkilerin değerlendirilmesi hedeflenmiştir.

\section{Gereç ve yöntem}

Ekolojik tipteki bu çalışmada ülkelerin COVID-19salgınıyaygınlığınındeğerlendirilmesi amacıyla ülkelere ait Worldometers internet sitesinde raporlanan veriler kullanılmıştır [8]. Salgının yaygınlığı ile ilgili 22 Ocak 2020-31 Temmuz 2020 tarihleri arasındaki COVID-19 ile ilişkili toplam vaka sayısı, toplam ölüm sayısı, toplam iyileşen sayısı, toplam test sayısı, günlük yeni vaka ve yeni ölüm sayısı, aktif vaka sayısı, ciddi/kritik vaka sayısı, milyonda toplam vaka sayısı, milyonda toplam ölüm sayısı, milyonda toplam test sayısı değerlendirmeye alınmıştır. Ülkelerin COVID-19 ilişkili değişkenleri ile ülkelerin Gini katsayıları, yaşlı nüfus popülasyonları, ekvatora uzaklıkları ve küresel sağlık güvenliği endeksleri arasındaki ilişkiye bakılmıştır. Gini katsayısı verisi World Population Review internet sitesinden [10], yaşlı nüfus popülasyonu verisi The World Bank internet sitesinden [11], ekvatora uzaklık verisi Google Developers internet sitesinden [12], küresel sağlık güvenliği endeksi verisi Global Health Security Index internet sitesinden [13] elde edilmiştir.

Gini katsayısı bir ulusun gelir dağılımını temsil etmeyi amaçlayan istatistiksel bir dağılım ölçüsüdür. 1912'de İtalyan istatistikçi Corrado Gini tarafından geliştirilmiştir ve gelir eşitsizliğinin en yaygın kullanılan ölçümüdür. 
Gini katsayısı, 0 ile 1 arasında değer alır. Gini katsayısının artması, daha büyük eşitsizlik olarak yorumlanır $(0=$ =mükemmel eşitlik, 1 =tam eşitsizlik hali).

Küresel Sağlık Güvenliği Endeksi (Global Health Security Index-GHS) Uluslararası Sağlık Tüzüğüne Taraf Devletleri oluşturan 195 ülkede sağlık güvenliği ve ilgili yeteneklerin kapsamlı değerlendirmesi ve kıyaslamasıdır. GHS Endeksi, Nükleer Tehdit Girişimi (NTI) ve Johns Hopkins Sağlık Güvenliği Merkezi'nin (JHU) bir projesidir ve The Economist Intelligence Unit (EIU) ile birlikte geliştirilmiştir.

GHS Endeksi ülkelerin yayınladığı veya uluslararası kuruluşlara bildirdiği açık kaynaklı bilgiler kullanılarak; 6 kategori, 34 gösterge ve 85 alt göstergede düzenlenmiş 140 soru ile oluşturulmuştur ve 100 üzerinden puanlandırılmaktadır. 6 kategorinin içeriği şu şekildedir [13]:

1. Önleme: Patojenlerin ortaya çıkmasının veya salınmasının önlenmesi

2. Tespit ve Raporlama: Potansiyel uluslararası endişe salgınları için erken tespit ve raporlama

3. Hızı Yanıt: Bir salgının yayılmasına hızlı yanit ve hafifletme

4. Sağlık Sistemi: Hastaları tedavi etmek ve sağlık çalışanlarını korumak için yeterli ve sağlam sağlık sistemi

5. Uluslararası Normlara Uygunluk: Ulusal kapasiteyi geliştirme taahhütleri, boşlukları gidermek için finansman planları ve küresel normlara bağlılık

6. Risk Ortamı: Genel risk ortamı ve biyolojik tehditlere karşı ülke savunmasızıı̆ı

Verilerin istatistiksel analizi için SPSS paket programı kullanılmış olup tanımlayıcı istatistikler için sayı, yüzde verilmiştir. Değişkenlerin normal dağılıma uygunluğu KolmogorovSmirnov testi ile değerlendirilmiş ve değişkenler arasındaki ilişki Spearman korelasyon testi ile incelenmiştir. Çok değişkenli lineer regresyon modeli kullanılarak farklı değişkenlerin birbirleri üzerindeki etkisi incelenmiştir. İstatistiksel anlamlılık düzeyi $p<0,05$ kabul edilmiştir.

Pamukkale Üniversitesi Girişimsel Olmayan Klinik Araştırmalar Etik Kurulu'ndan ve Sağlık Bakanlığı'ndan gerekli izinler alınmıştır.

\section{Bulgular}

Araştırmada 215 ülke değerlendirmeye alınmıştır. COVID-19 toplam vaka ve ölüm sayılarının en fazla görüldüğü ülkeler sırasıyla Amerika Birleşik Devletleri (ABD) ve Brezilya'dır. Milyonda toplam vaka sayısının en fazla görüldüğü ülke Katar iken; milyonda toplam ölüm sayısı en fazla San Marino'da, milyonda toplam test sayısı en fazla Monako'dadır (Tablo 1). Sağlık güvenliği endeksi en yüksek olan ülkeler sırasıyla ABD $(83,5)$, Birleşik Krallık $(77,9)$, Hollanda $(75,6)$, Avustralya $(75,5)$ ve Kanada'dır $(75,3)$.

Ülkelerin milyonda toplam vaka, milyonda toplam ölüm ve milyonda toplam test sayıları ile ilişkili faktörleri araştırmak için yaptığımız korelasyon analizinde Gini katsayısı ile milyonda toplam test negatif yönde, düşükorta derecede korele bulunmuştur ( $r=-0,346$; $p<0,001)$, Gini katsayısı arttıkça milyonda toplam test azalmaktadır (Tablo 2). Ekvatora uzaklık milyonda toplam vaka ve milyonda toplam ölüm ile pozitif yönde düşük-orta derecede $(r=0,353 ; p<0,001$ ve $r=0,347$; $p<0,001)$; milyonda toplam test ile pozitif yönde orta derecede korele bulunmuştur $(r=0,562$; $p<0,001)$. Ekvatora uzaklık arttıkça milyonda toplam vaka, milyonda toplam ölüm ve milyonda toplam test artmaktadır (Tablo 2). Yaşlı nüfus milyonda toplam vaka ile pozitif yönde düşükorta derecede $(r=0,310 ; p<0,001)$; milyonda toplam toplam ölüm ve milyonda toplam test ile pozitif yönde orta derecede koreledir $(r=0,406$; $p<0,001$ ve $r=0,548 ; p<0,001)$. Yaşlı nüfus arttıkça milyonda toplam vaka, milyonda toplam ölüm ve milyonda toplam test artmaktadır (Tablo 2). Sağlık güvenliği endeksi (GHS) milyonda toplam vaka ile düşük-orta $(r=0,367 ; p<0,001)$; milyonda toplam ölüm ve milyonda toplam test ile orta derecede koreledir $(r=0,442 ; p<0,001$ ve $r=0,523 ; p<0,001)$. GHS arttıkça milyonda toplam vaka, milyonda toplam ölüm ve milyonda toplam test artmaktadır (Tablo 2). 
Tablo 1. Toplam vaka, toplam ölüm, milyonda toplam vaka, milyonda toplam ölüm ve milyonda toplam test sayılarının en fazla olduğu ülkeler

\begin{tabular}{|c|c|c|}
\hline Değişken & Ülke & Sayı \\
\hline \multirow[t]{5}{*}{ Toplam Vaka Sayısı } & $\mathrm{ABD}$ & 4652841 \\
\hline & Brezilya & 2613789 \\
\hline & Hindistan & 1677853 \\
\hline & Rusya & 839981 \\
\hline & Güney Afrika & 482169 \\
\hline \multirow[t]{5}{*}{ Toplam Ölüm Sayısı } & ABD & 155716 \\
\hline & Brezilya & 91377 \\
\hline & Birleşik Krallık & 46119 \\
\hline & Meksika & 46000 \\
\hline & Hindistan & 36185 \\
\hline \multirow[t]{5}{*}{ Milyonda Toplam Vaka Sayısı } & Katar & 39424 \\
\hline & Fransız Guyanası & 25826 \\
\hline & Bahrain & 23896 \\
\hline & San Marino & 20597 \\
\hline & Şili & 18481 \\
\hline \multirow[t]{5}{*}{ Milyonda Toplam Ölüm Sayısı } & San Marino & 1238 \\
\hline & Belçika & 849 \\
\hline & Birleşik Krallık & 679 \\
\hline & Andorra & 673 \\
\hline & İspanya & 608 \\
\hline \multirow[t]{5}{*}{ Milyonda Toplam Test Sayısı } & Monako & 973106 \\
\hline & Faroe Adaları & 755391 \\
\hline & Lüksemburg & 654868 \\
\hline & Gibraltar & 630573 \\
\hline & Falkland Adaları & 520792 \\
\hline
\end{tabular}

Tablo 2. Ülkelerin COVID-19 vaka, ölüm ve test sayılarıyla, Gini katsayıları, ekvatora uzaklıkları, yaşlı nüfus oranları ve sağlık güvenliği endeksleri arasındaki korelasyon düzeyleri

\begin{tabular}{llllll}
\hline & & Gini katsayısı & Ekvatora uzaklık & Yaşlı nüfus oranı & $\begin{array}{l}\text { Sağlık güvenliği } \\
\text { endeksi }\end{array}$ \\
\hline Milyonda toplam & $\mathbf{r}$ & $-0,118$ & 0,353 & 0,310 & 0,367 \\
vaka & $\boldsymbol{p}$ & 0,165 & $<0,001$ & $<0,001$ & $<0,001$ \\
Milyonda toplam & $\mathbf{r}$ & $-0,172$ & 0,347 & 0,406 & 0,442 \\
Ölüm & $\boldsymbol{p}$ & 0,042 & $<0,001$ & $<0,001$ & $<0,001$ \\
Milyonda Toplam & $\mathbf{r}$ & $-0,346$ & 0,562 & 0,584 & 0,523 \\
test & $\boldsymbol{p}$ & $<0,001$ & $<0,001$ & $<0,001$ & $<0,001$ \\
\hline
\end{tabular}

Ülkelerin milyonda toplam vaka, milyonda toplam ölüm ve milyonda toplam test sayılarına etki eden faktörleri araştırmak için, modele ülkelerin Gini katsayısı, yaşlı nüfus oranları ve ekvatora uzaklıklarını dahil ederek yaptığımız doğrusal regresyon analizi sonucunda Gini katsayısının milyonda toplam vaka sayısını, yaşı nüfus oranlarının milyonda toplam ölüm sayısını, ekvatora uzaklıklarının milyonda toplam test sayısını etkilediği saptanmıştır. Ülkelerin Gini katsayıları arttıkça milyonda toplam vaka sayıları $(p=0,006)$ (Tablo 3) (Şekil 1 ve 2) [10, 14]; yaşlı nüfus oranları arttıkça milyonda ölüm sayıları $(p=0,005)$ (Tablo 4$)$ (Şekil 3 ve 4) [11, 14]; ekvatora uzaklıkları arttıkça milyonda test sayıları $(p=0,015)$ (Tablo 5) (Şekil 5) [15] artmaktadır. 
Tablo 3. Milyonda vaka sayısını etkileyen faktörlerle ilgili regresyon modeli*

\begin{tabular}{llll}
\hline & B & Standart hata & $\boldsymbol{p}$ \\
\hline Gini katsayısı & 11783,779 & 4232,866 & 0,006 \\
\hline
\end{tabular}

*Modele ülkelerin Gini katsayısı, ekvatora uzaklığı, yaşı nüfus popülasyonları dahil edilerek doğrusal regresyon analizi yapılmıştır $\mathrm{R}^{2}=0,095$
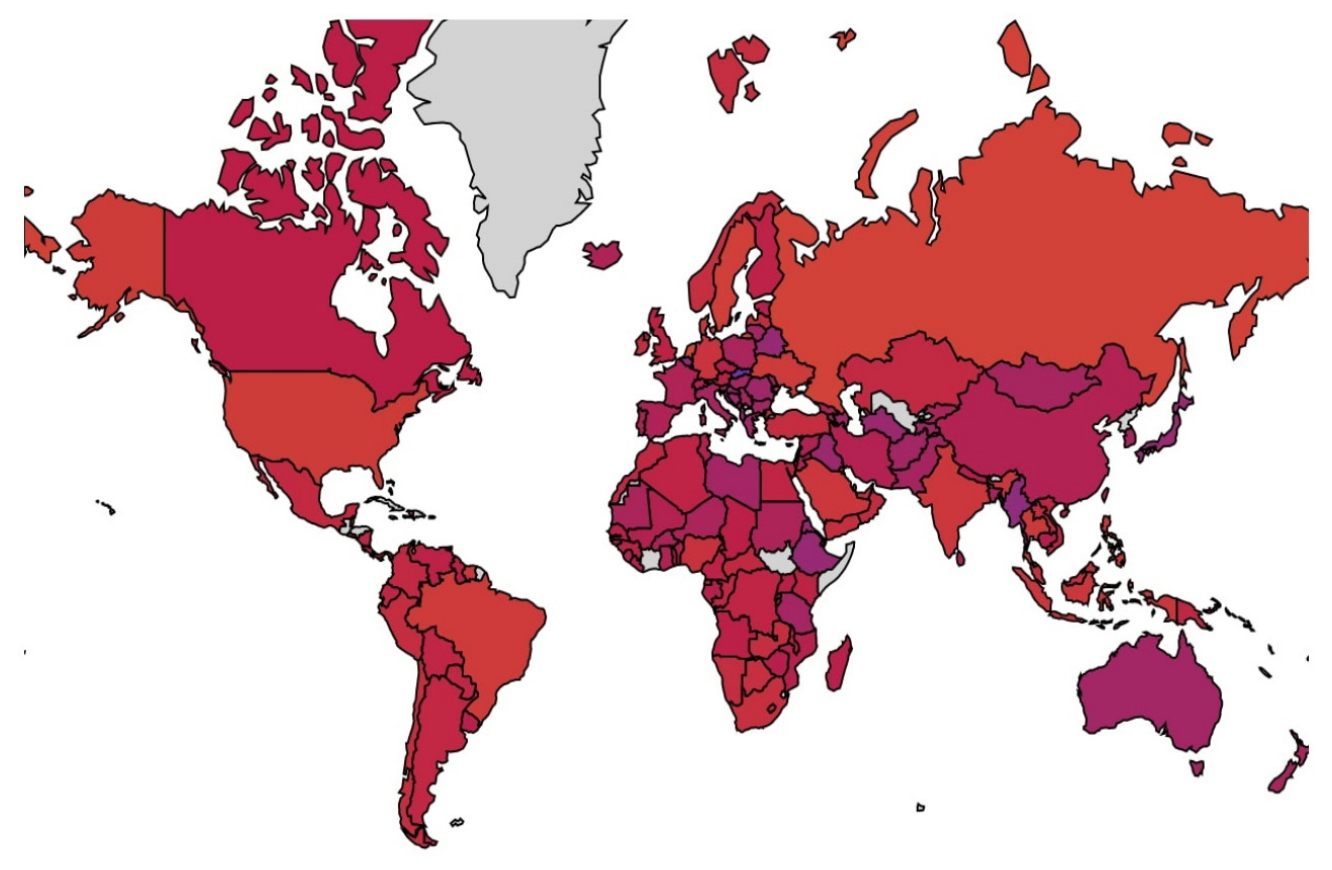

Gini Index

< $0.5 \square>0.5 \square>0.55 \square>0.6 \square>0.65 \square>0.7 \square>0.75 \square>0.8 \square>0.85 \square>0.9 \square>0.95$

Şekil 1. Ülkelere göre 2020 yılı Gini katsayıları

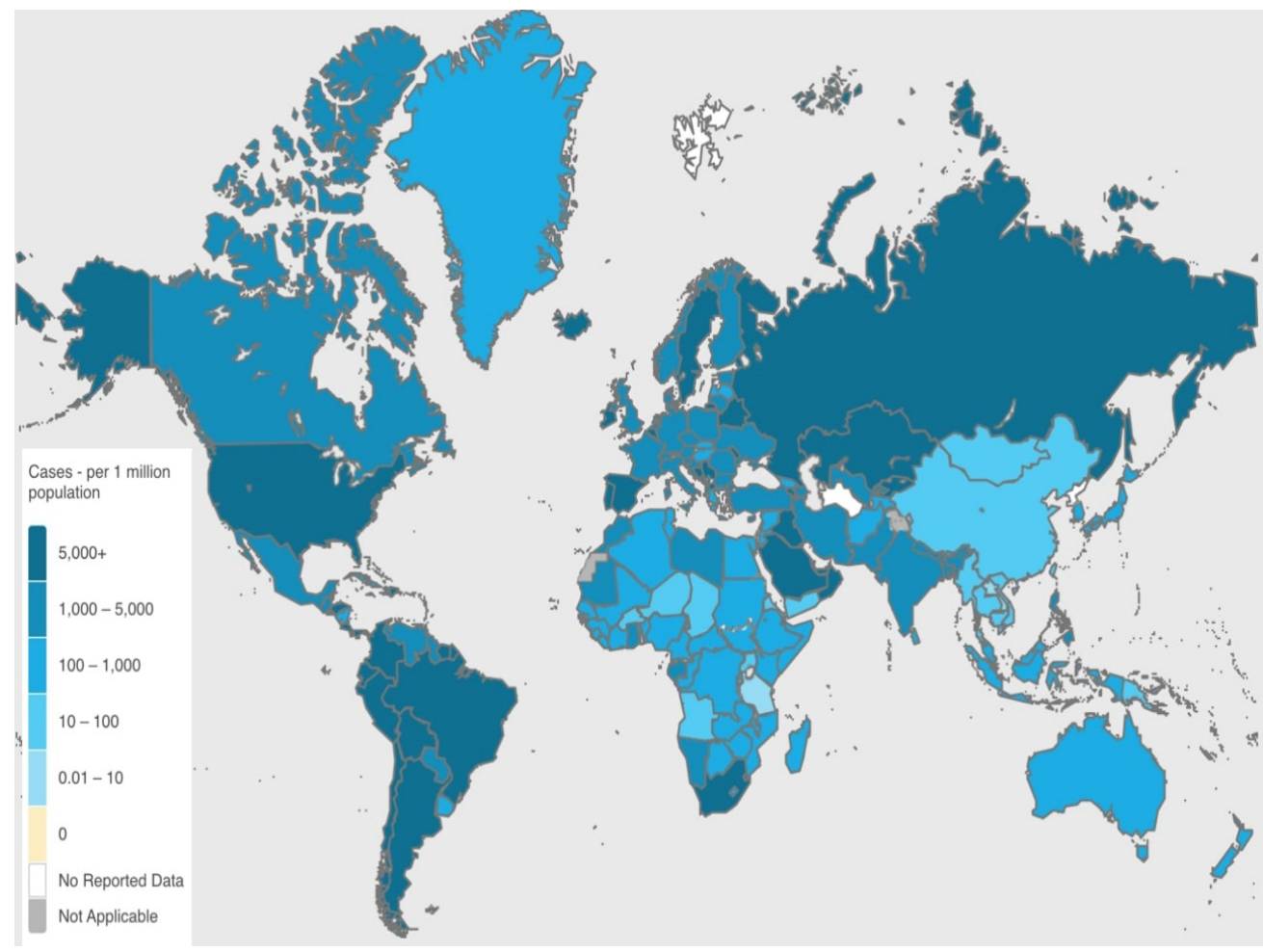

Şekil 2. Ülkelere göre milyonda vaka sayıları 
Tablo 4. Milyonda ölüm sayısını etkileyen faktörlerle ilgili regresyon modeli*

\begin{tabular}{llll}
\hline & B & Standart hata & $\boldsymbol{p}$ \\
Yaşlı nüfus & 8,493 & 2,982 & 0,005 \\
\hline
\end{tabular}

*Modele ülkelerin Gini katsayısı, ekvatora uzaklığı, yaşıı nüfus popülasyonları dahil edilerek doğrusal regresyon analizi yapıımıştır $\mathrm{R}^{2}=0,159$

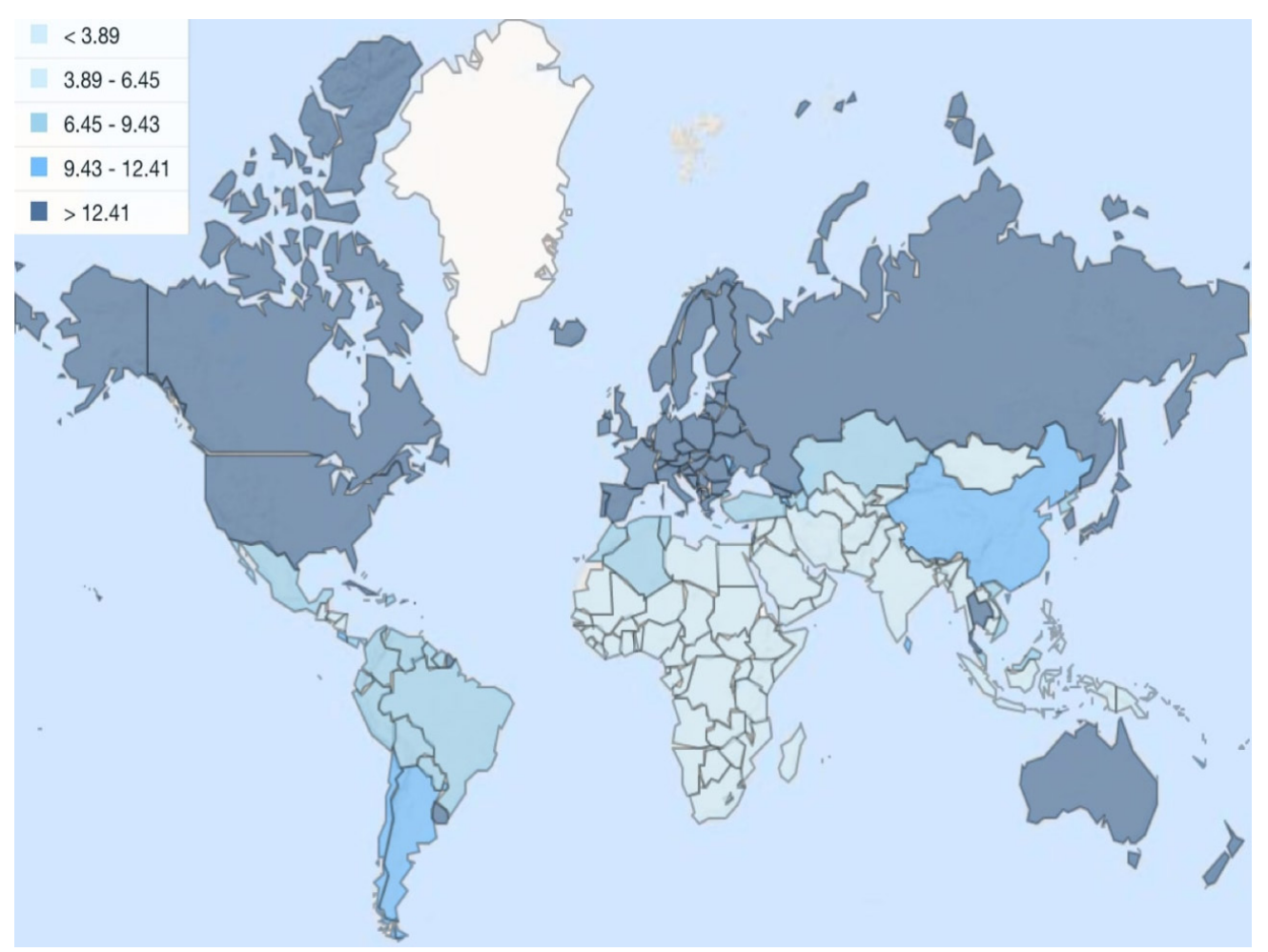

Şekil 3. Ülkelerin 65 yaş ve üstü nüfus popülasyonları (\%)

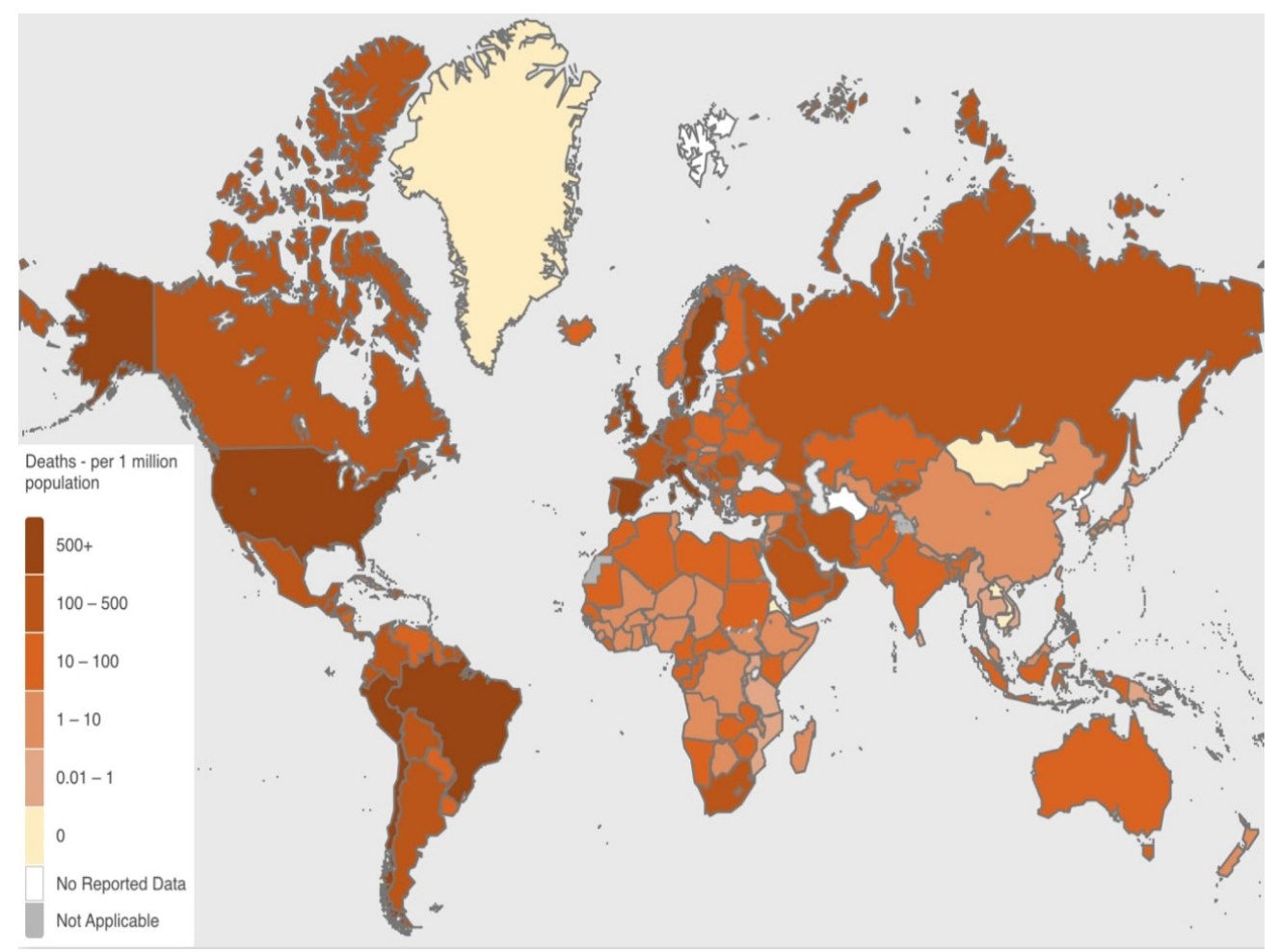

Şekil 4. Ülkelere göre milyonda ölüm sayıları 
Tablo 5. Milyonda test sayısını etkileyen faktörlerle ilgili regresyon modeli*

\begin{tabular}{llll}
\hline & B & Standart Hata & $\boldsymbol{p}$ \\
\hline Ekvatora uzaklık & 1526,389 & 617,042 & 0,015 \\
\hline
\end{tabular}

* Modele ülkelerin Gini katsayısı, ekvatora uzaklığı, yaşlı nüfus popülasyonları dahil edilerek doğrusal regresyon analizi yapılmıştır $\mathrm{R}^{2}=0,230$

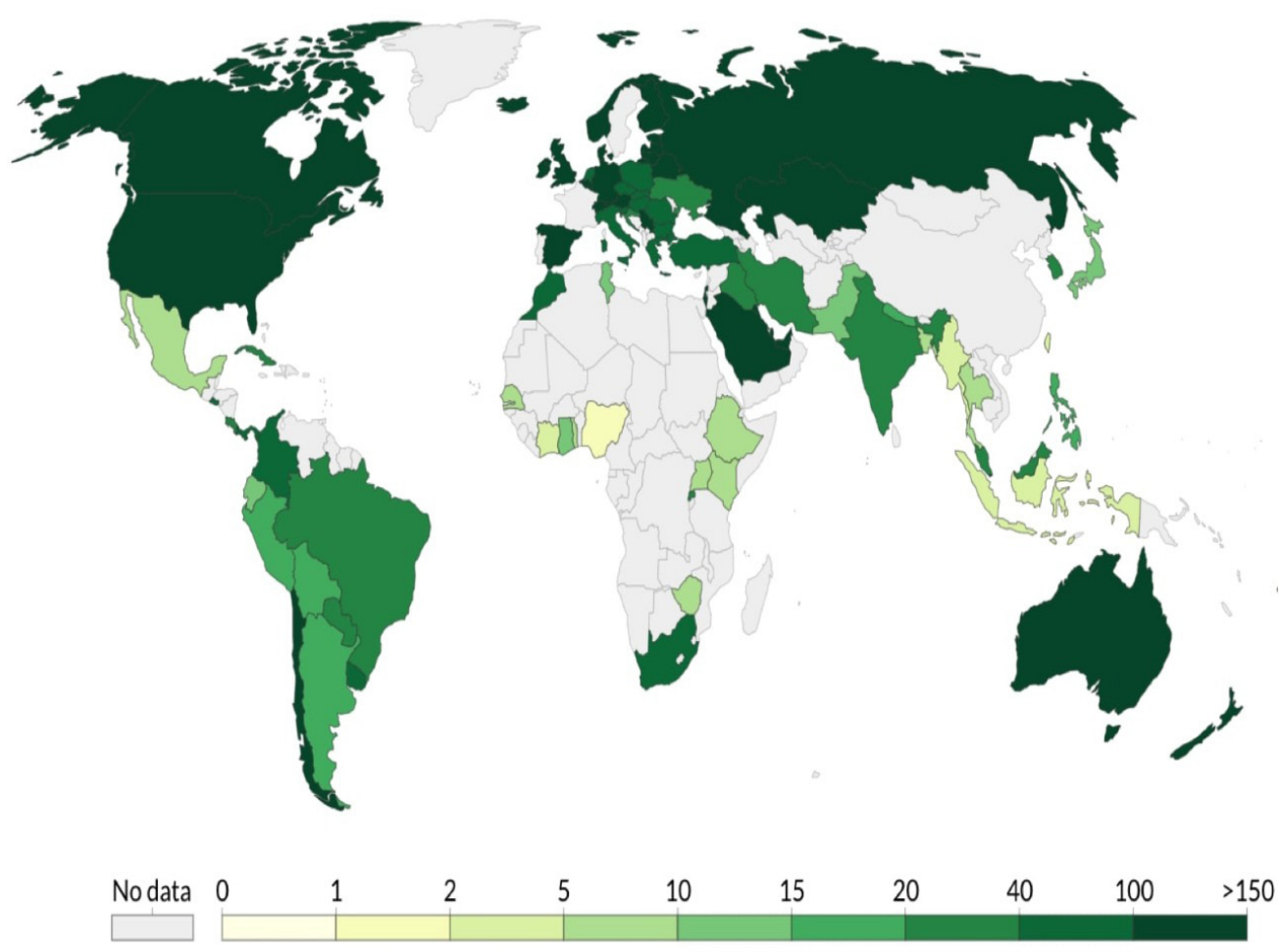

Şekil 5. Ülkelere göre binde test sayıları

\section{Tartışma}

Araştırmamızda COVID-19 yaygınlığının ülkelerin Gini katsayısı, yaşlı nüfus popülasyonu ve ekvatora uzaklıkları ile ilişkili olduğu saptanmıştır.

Araştırmamızda ülkelerin milyonda vaka sayısı ile Gini katsayısı ilişkili bulunmuştur. Pandemilerin tüm insanları aynı şekilde etkilememesi beklenen bir durumdur. Çocuklar, yaşlılar, engelliler, yoksullar gibi incinebilir gruplar dış etkenlere daha açıktır. Gelir eşitsizliği başta olmak üzere çeşitli eşitsizlikler bulaşma ve ölüm oranlarını kötüleştirebilir. Örneğin 14. yüzyılda kara ölüm olarak da anılan vebanın taşralı göçmenler, hizmetçiler gibi yoksul insanları daha çok etkilediği bilinmektedir [16].

Bir toplumda gelir eşitsizliğinin artması insanların yaşam koşullarını etkilemekte, dar gelirli insanların daha küçük yerlerde daha kalabalık yaşamak durumunda kalmaları sonucu enfeksiyona daha açık hâle gelmelerine neden olmaktadır. Ayrıca bu eşitsizlik sağlık hizmetlerine erişimde eşitsizliklere neden olmakta ve yoksul kesimi daha fazla risk altında bırakmaktadır [17]. Bu bakımdan COVID-19 salgınının Gini katsayısı yüksek ülkelerde daha yaygın görülmesi şaşırtıcı değildir. Öte yandan salgını kontrol altına almak için getirilen karantina, okulların, işyerlerinin kapatılması gibi önlemler sonucu ortaya çıkan artan işsizlik ve ekonomik durgunluğun mevcut sosyoekonomik eşitsizlikleri daha da derinleştirebileceği düşünülebilir [18].

Araştırmamızda ülkelerin milyonda ölüm sayısı ile yaşlı nüfus oranı arasında ilişki olduğu saptanmıştır. Bu bulgu salgının başından itibaren COVID-19 enfeksiyonunun yaşlılarda daha ağır ve ölümcül geçirildiği gözlenmiş olduğundan beklediğimiz bir niteliktedir. Hipertansiyon, diyabet, kardiyovasküler hastalıklar, kronik akciğer hastalıkları gibi kronik hastalıklara sahip bireyler enfeksiyonu daha şiddetli geçirmektedir. 
$\mathrm{Bu}$ hastalıkların yaş ilerledikçe sıklığının artmasıyla bu komorbiditeler COVID-19 ile ilişkili komplikasyonları ve ölüm oranlarını artırmaktadır [19]. Ölüm oranlarının yaşa bağlı artış gösterdiğine dair tutarlı modeller mevcuttur. Kore Hastalık Kontrol ve Önleme Merkezi (KCDC)'ne göre 25 Ağustos tarihinde 17.945 doğrulanmış vakada genel ölüm oranı $\% 1,7$ iken 29 yaş ve altında ölüm görülmemekte, 60 yaş ve üzerinde $\% 13,23$ ile $\% 49,68$ arasında değişmektedir [20]. Hastalık Kontrol ve Önleme Merkezi (CDC)'nin raporladığı $A B D$ verilerinde de ölümlerin yaş arttıkça arttığı görülmektedir [21]. İngiltere'de birinci basamak sağlık hizmeti alan 17 milyon hasta ile yapılan araştırmada COVID-19 ölüm riskinin yaşla korele olduğu belirtilmektedir [22]. Benzer şekilde 31 Temmuz 2020 itibariyle yaşlı nüfus oranı \%1,5 olan Katar'da milyonda ölüm 62 iken; yaşlı nüfus oranı \%20,2 olan İsveç'te milyonda ölüm 568'dir [8]. Bu farklılığın nedeni; ülkelerin tüm COVID-19 ölümlerini tespit etme ve bildirme durumlarındaki varyasyonlar, hastalığın farklı aşamalarında uygulanan farklı kalitede bakım veya müdahaleler olabileceği gibi yaş, cinsiyet, etnik köken ve altta yatan komorbidite gibi özelliklerle oluşan hasta profillerindeki çeşitlilik olabilir [23].

Araştırmamızda ülkelerin milyonda test sayısı ile ekvatora uzaklığı ilişkili bulunmuştur. Ekvatora uzaklık arttıkça test sayısı artmaktadır. Uygulanan test sayısıyla ülkenin ekvator kuşağına olan uzaklığı arasındaki ilişkiye yönelik somut bir açıklama bulmanın güçlüğüne rağmen bu ilişkinin temelde ekvatora uzak olan ülkelerin nüfus yoğunluğunun daha fazla olmasıyla bağlantılı olabileceğini düşünmekteyiz. 25 Nisan 2020 tarihinde tüm dünyadaki vakaların \%70'inin $35^{\circ}$ ila $50^{\circ}$ $\mathrm{N}$ enlemleri arasında bulunan ülkelerden bildirildiği gözlenmiştir [24]. Amerika'daki vaka sayıları dünya genelindeki vakaların \%26'sını oluşturmaktadır [8]. Dolayısıyla nüfusun yoğun olması vaka sayısının yüksekliğine dolayısıyla gerekli test sayısının artışına yol açıyor olabilir.

Diğer taraftan ülkelerin GHS düzeyindeki artışla milyonda vaka, ölüm ve test sayıları arasında pozitif yönde korelasyon olduğu saptanmıştır. Bu bulgu aslında beklentimize uygun değildi. Araştırmanın başında önleme, tespit, raporlama, hızı müdahale, sağlık sistemi, salgın hastalıklara karşı ulusal kapasite ve risk ortamı faktörünü dikkate alan GHS endeksinin [24]; salgının yayılımı üzerinde olumlu bir etkisi olacağını, GHS ne kadar yüksekse vaka ve ölümün o kadar az görüleceğini düşünmüştük ancak ters yönde bir ilişki gözlemledik. Bunun olası sebebi salgını yoğun yaşayan ülkelerin mecburen önlemlerini arttırması sonucu GHS endekslerinin yükseliyor olması olabilir. Yani başlangıçta "neden" olarak düşündüğümüz GHS endeksinin gerçekte bir "sonuç" olduğu kanaatine vardık.

COVID-19ileilgilikullandığımızverikaynakları ülkelerin resmi olarak yayınladıkları verilere dayanmaktadır ve çalışma sonuçlarımızın güvenilirliğinin bu verilerin güvenilirlik düzeyine dayalı olması araştırmamızın kısıtlıığıdır. Bununla birlikte her ülke böyle bir bildirimde bulunmadığı için mevcut tüm ülkeler çalışmaya dahil edilememiştir.

Çalışmamızın yapıldığı tarih itibariyle güncel nitelikli olan ve hemen hemen tüm ülke verilerine ulaşılarak elde edilmiş olan veriler salgını küresel boyutta ele alma olanağı sağlamıştır. Çalışmada analiz edilen salgınla ilişkili olası faktörlerin hem demografik hem sosyoekonomik hem de coğrafi bir kapsama sahip olması daha geniş bir bakış açısıyla değerlendirme olanağı sağlaması araştırmamızın güçlü yanıdır.

Sonuç olarak; gelir eşitsizliği, yaşlı nüfus, ekvatora uzaklık arttıkça salgından etkilenim artmaktadır. Dolayısıyla salgının eşitsizlikleri azaltmayı amaçlayan politikalar geliştirilmesi ve özellikle ileri yaşlarda artan komorbit hastalıkları önlemeye yönelik programlar yürütülmesi ile olan ilişkilerini daha derinlemesine ortaya koyabilecek ileri çalışmalara gereksinim vardır.

Çıkar ilişkisi: Yazarlar çıkar ilişkilerinin olmadığını beyan ederler.

\section{Kaynaklar}

1. Klinik Mikrobiyoloji Uzmanlık Derneği, MERS virüsü hakkında bilgilendirme. Erişim adresi: https://www. klimud.org/content/260/mers-virusu-hakkindabilgilendirme. Erişim tarihi 16 Ağustos 2020

2. T.C. Sağlık Bakanlığı Halk Sağlığı Genel Müdürlüğü, COVID-19 (SARS-COV-2 Enfeksiyonu) Rehberi, 2020. Erişim adresi: https://covid19.saglik.gov.tr/ Eklenti/38657/0/covid-19salginyonetimivecalismarehb eripdf.pdf?_tag1 $=$ C7FBE4BB73B1776FCC3F413BA0 EDFBD6B2D82672. Erişim tarihi 15 Ağustos 2020 
3. Chen Q, Liu Y, Wang FL. A Chronicle on the SARS Epidemic. Chinese Law and Government 2003;36:1215. https://doi.org/10.2753/CLG0009-4609360412

4. Middle East respiratory syndrome coronavirus (MERSCoV). Avaliable at: https://www.who.int/news-room/ fact-sheets/detail/middle-east-respiratory-syndromecoronavirus-(mers-cov). Accessed August 16, 2020

5. MERS outbreak in the Republic of Korea, 2015. Avaliable at: https://www.who.int/westernpacific/ emergencies/2015-mers-outbreak. Accessed August 16, 2020

6. Coronavirus disease 2019 (COVID-19) situation report-94. Avaliable at: https://www.who.int/ docs/default-source/coronaviruse/situationreports/20200423-sitrep-94-covid-19.pdf?sfvrsn=b83 04bf0_4\#: :text=humans\%20since\%202012.-,All\%20 available $\% 20$ evidence $\% 20$ for $\% 20$ COVID $\% 2$ D $19 \% 20$ suggests $\% 20$ that $\% 20$ SARS $\% 2$ DCoV,to $\% 20$ be $\% 20$ handled\%20by\%20humans. Accessed August 16, 2020

7. Kang SJ, Jung SI. Age-related morbidity and mortality among patients with COVID-19. Infect Chemother 2020;52:154-164. https://doi.org/10.3947/ ic. 2020.52.2.154

8. COVID-19 Coronavirus pandemic. Avaliable at: https:// www.worldometers.info/coronavirus/?. Accessed July 31,2020

9. Cesari M, Proietti M. COVID-19 in Italy: ageism and decision making in a pandemic. J Am Med Dir Assoc 2020;21:576-577. https://doi.org/10.1016/j. jamda.2020.03.025

10. World Population Review. Gini coefficient by country 2020. Avaliable at: https://worldpopulationreview.com/ country-rankings/gini-coefficient-by-country. Accessed August 15, 2020

11. The World Bank Group. The World Bank. Available at: https://data.worldbank.org/indicator/SP.POP.65UP. TO.ZS. Accessed August 29, 2020

12. Google developers public data. Available at: https:// developers.google.com/public-data/docs/canonical/ countries_csv. Accessed July 31, 2020

13. GSH Index. Global health security index. Avaliable at: https://www.ghsindex.org/about/. Accessed August 7, 2020

14. World Health Organization. WHO Coronavirus disease (COVID-19) dashboard. Available at: https://covid19. who.int/. Accessed August 29, 2020

15. Our World in Data. Coronavirus (COVID-19) testing. Available at: https://ourworldindata.org/coronavirustesting. Accessed August 29, 2020

16. Duncan CJ, Scott S. What caused the Black Death? Postgraduate Med J 2005;81:315-320. https://doi. org/10.1136/pgmj.2004.024075
17. Hiscott J, Alexandridi M, Muscolini M, et al. The global impact of the coronavirus pandemic. Cytokine and Growth Factor Reviews 2020;53:1-9. https://doi. org/10.1016/j.cytogfr.2020.05.010

18. Mikolai J, Keenan K, Kulu H. Intersecting household level health and socio-economic vulnerabilities and the COVID-19 crisis: an analysis from the UK. SSM - Population Health 2020;12:100628. https://doi. org/10.1016/j.ssmph.2020.100628

19. Hewitt J, Carter B, Vilches Moraga A, et al. The effect of frailty on survival in patients with COVID-19 (COPE): a multicentre, European, observational cohort study. The Lancet Public Health 2020;5:444-451. https://doi. org/10.1016/S2468-2667(20)30146-8

20. Coronavirus disease-19, republic of Korea. Available at: http://ncov.mohw.go.kr/bdBoardList_Real.do?brd $\mathrm{Id}=1 \&$ brdGubun=11\&ncvContSeq= \& contSeq=\&boa rd_id=\&gubun=. Accessed August 25, 2020

21. Centers for disease control and prevention. Available at: https://www.cdc.gov/nchs/nvss/vsrr/covid_weekly/ index.htm\#AgeAndSex. Accessed August 25, 2020

22. Williamson EJ, Walker AJ, Bhaskaran $\mathrm{K}$, et al. Factors associated with COVID-19-related death using OpenSAFELY. Nature 2020;584:430-436. https://doi. org/10.1038/s41586-020-2521-4

23. World Health Organization. Estimating mortality from COVID-19. Available at: https://www.who.int/newsroom/commentaries/detail/estimating-mortality-fromcovid-19. Accessed August 25, 2020

24. Chennakesavulu K, Reddy GR. The effect of latitude and PM2.5 on spreading of SARS-CoV-2 in tropical and temperate zone countries. Environ Pollut 2020;266:115176. https://doi.org/10.1016/j. envpol.2020.115176

Teşekkür: Katkılarından dolayı Özgecan Elçi, Şebnem Erten, Mert Hamit Haliloğlu, Orçun Burak Karadağ, Merve Tuğana Keskin, Elifnaz Keskin, Gülşen Korkut, Ümmühan Betül Köseoğlu, Kübra Yıldız, Melike Köroğlu, Ebru Şen, Büşra Fışkın, İsmail Salih Alacalı, Rukiye Elif Başın, Ferhat Perk, Emre Sağ, İrem Sarıca, Merve Satılmış, Şeyma Gülsüm Şencan, Neslihan Türk, Mukaddes Kübra Uçar ve Oğuzhan Yıldırım'a teşekkür ederiz.

Etik kurul onayı: Pamukkale Üniversitesi Girişimsel Olmayan Klinik Araştırmalar Etik Kurulu'ndan 25/08/2020 tarih ve 60116787020/50337 sayı ile onay alınmıştır. 


\section{Yazarların makaleye olan katkıları}

Ö.S. ve C.O. çalışmanın ana fikrini ve hipotezini kurgulamışlardır. Ö.S. ve C.O. teoriyi geliştirmiş, gereç ve yöntem bölümünü düzenlemişlerdir. Sonuçlar kısmındaki verilerin değerlendirmesini Ö.S., C.O. ve E.B. yapmışlardır. Makalenin tartışma bölümü Ö.S. ve C.O. tarafından yazılmış, Ö.S., C.O. ve E.B. gözden geçirip gerekli düzeltmeleri yapmış ve onaylamıştır. Ayrıca tüm yazarlar çalışmanın tamamını tartışmış ve son halini onaylamıştır. 